\title{
Role of Tissue Transglutaminase Catalytic and Guanosine Triphosphate-Binding Domains in Renal Cell Carcinoma Progression
}

\author{
Burge Ulukan, Ajna Bihorac, Tarik Sipahioglu, Robert Kiraly, Laszlo Fesus, and Dilek Telci*
}

Cite This: ACS Omega 2020, 5, 28273-28284

Read Online

ABSTRACT: Tissue transglutaminase (TG2) is a multifunctional protein that can act as a cross-linking enzyme, GTPase/ATPase, protein kinase, and protein disulfide isomerase. TG2 is involved in cell adhesion, migration, invasion, and growth, as well as epithelial-mesenchymal transition (EMT). Our previous findings indicate that the increased expression of TG2 in renal cell carcinoma (RCC) results in tumor metastasis with a significant decrease in disease- and cancer-specific survival outcome. Given the importance of the prometastatic activity of TG2 in RCC, in the present study, we aim to investigate the relative contribution of TG2's transamidase and guanosine triphosphate (GTP)-binding/ GTPase activity in the cell migration, invasion, EMT, and cancer

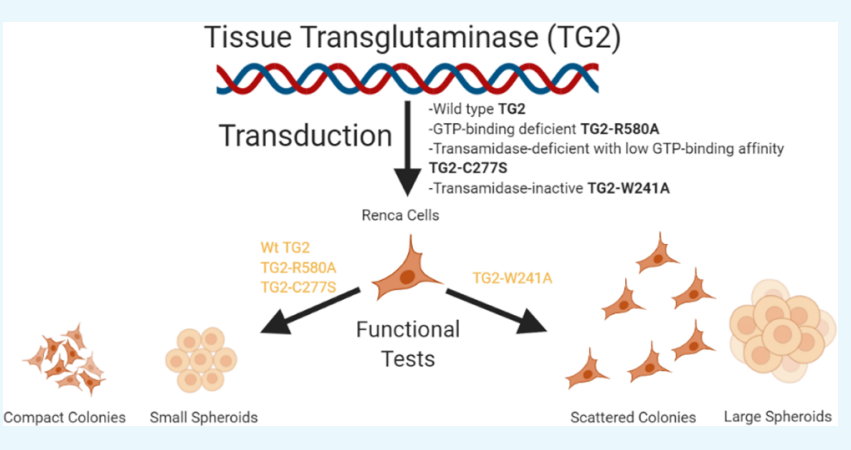
stemness of RCC. For this purpose, the mouse RCC cell line RenCa was transduced with wild-type-TG2 (wt-TG2), GTP-binding deficient-form TG2-R580A, transamidase-deficient form with low GTP-binding affinity TG2-C277S, and transamidase-inactive form TG2-W241A. Our results suggested that predominantly, GTP-binding activity of TG2 is responsible for cell migration and invasion. In addition, CD marker analysis and spheroid assay confirmed that GTP binding/GTPase activity of TG2 is important in the maintenance of mesenchymal character and the cancer stem cell profile. These findings support a prometastatic role for TG2 in RCC that is dependent on the GTP binding/GTPase activity of the enzyme.

\section{INTRODUCTION}

Tissue transglutaminase (TG2), a ubiquitously expressed enzyme with pleiotropic functions, catalyzes several reactions including $\mathrm{Ca}^{2+}$-dependent protein-protein cross-linking, protein disulfide isomerase, serine/threonine kinase activity, and guanosine triphosphate (GTP)/ guanosine diphosphate (GDP)-bindingGTPase activity. ${ }^{1}$ TG2 consists of four main domains including $\beta$-sandwich domain with the fibronectin (FN) binding site, catalytic core domain with Cys-His-Asp catalytic triad and $\mathrm{Ca}^{2+}$ binding site, and two $\beta$-barrel domains with GTPase activity and PLC-binding site at the C-terminus. TG2 is present in different cellular locations such as cytoplasm, nucleus, mitochondria, cell surface, and also in the extracellular matrix (ECM). ${ }^{2,3}$ TG2 expression is associated with the regulation of survival signaling, cell proliferation, cell migration, and invasion, along with the integrin-mediated cell adhesion, cancer stemness, epithelial-mesenchymal transition (EMT), and drug resistance. ${ }^{4}$

Among its other functions, TG2 can act as a cell adhesion protein by forming a complex with $\mathrm{FN}$, an essential ECM glycoprotein. This complex is recognized by the heparan sulfate proteoglycan syndecan-4 (SDC-4) and triggers a signaling cascade that contributes to the regulation of cell adhesion and survival through the integrin $\beta 1$ (ITG $\beta 1$ ) activation. $^{5-9}$ Recent studies indicated that TG2 in association with ITG $\beta 1$ was involved in the promotion of tumorigenesis and progression in epithelially originated cancers. ${ }^{5,10}$ Accumulating evidence suggested that the overexpression of TG2 together with ITG $\beta 1$ led to a more invasive and mesenchymal phenotype, enhanced cell survival, and the acquisition of drug resistance in multiple cancer types, including ovarian, ${ }^{11}$ breast, ${ }^{10,12-15}$ and pancreatic cancer. ${ }^{16}$ As the upregulation of ITG $\beta 1$ is an established marker for EMT, ${ }^{17}$ recent studies focused on the involvement of TG2 in EMT progression. ${ }^{3}$ Analysis of cell invasiveness and tumor metastasis potential in breast, ${ }^{10,12,13,18,19}$ ovarian, ${ }^{11,20,21}$ epidermoid, ${ }^{22,23}$ melanoma, ${ }^{24}$ and colorectal cancers ${ }^{25,26}$ showed that TG2 expression was linked with oncogenic signaling pathways involved in EMT and in the maintenance of the cancer stem cell (CSC) profile. Hence, in order to design novel therapeutic strategies that aim to increase drug sensitivity and suppress metastasis, a comprehensive understanding of molecular mechanisms in TG2-mediated EMT came into prominence. ${ }^{27,28}$

Received: August 31, 2020

Accepted: October 6, 2020

Published: October 20, 2020

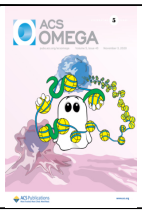


A

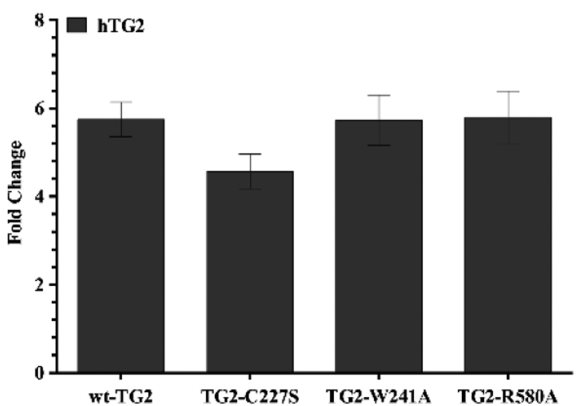

B

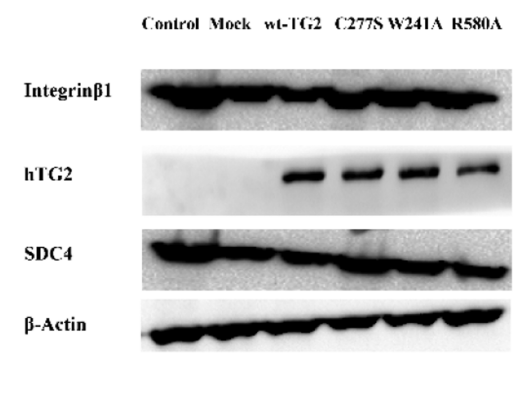

C

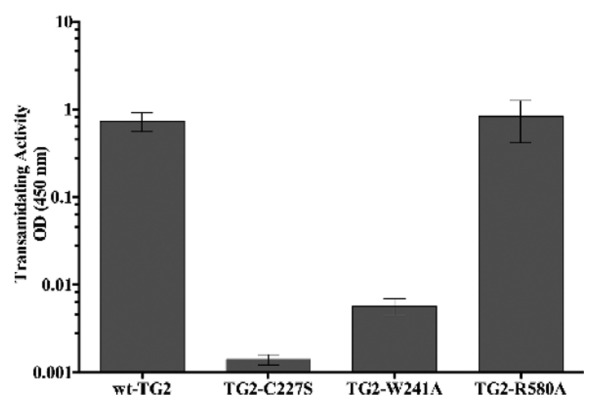

Figure 1. Expression of transglutaminase 2 constructs in RenCa cells. (A) Relative TG2 expression RenCa cells transduced with the lentiviral vector carrying wt-TG2, transamidase-defective form with low GTP-binding affinity (TG2-C277S), GTP-binding deficient form (TG2-R580A), and transamidase-inactive form (TG2-W241A). 18S mRNA was used to normalize TGM2 mRNA levels (mean \pm SD of the mean for three independent experiments). (B) Representative immunoblots showing TG2 protein levels along with ITG $\beta 1$ and SDC4 protein expression in parental RenCa cells (control) and in RenCa cells transduced with backbone eGFP plasmid (Mock) and TG2 mutant constructs. $\beta$-Actin was used as the loading control protein. (C) TG2 transamidating activity of TG2 constructs was determined using TG2-CovTest-specific colorimetric microassay kit.

According to the American Cancer Society, renal cell carcinoma (RCC) is characterized by high frequency of metastasis and poor prognosis outcome. It is the sixth most severe cause of cancer death, and approximately $90 \%$ of the kidney cancer cases are RCC. If detected in early stages, RCC is potentially curable with a surgical resection approach, yet there is no curative treatment for the metastatic RCC (mRCC). ${ }^{29}$ Therefore, identification of a drug-targetable protein that is essential for the survival and metastasis of RCC is of paramount importance for treatment of the disease. A few studies showed that, TG2 is important in RCC development and tumorigenesis. ${ }^{30,31}$ Previously, we showed that TG2 gene expression was increased concomitantly with SDC4 and ITG $\beta 1$ in mRCC, $^{32}$ resulting in a significant decrease in disease- and cancer-specific survival outcome. ${ }^{30,32}$ Moreover, silencing of TG2 in primary and metastatic site human RCC cell lines resulted in an impaired adhesion, migration, and invasive capacity. ${ }^{33}$ Several studies suggested that the interaction of TG2 with DNA-binding domain of p53 through its $\mathrm{N}$-terminal domain mediates the transportation of p53 to autophagosome, which leads to the degradation of p53 $33^{34,35}$ and hence increase the tumor cell survival rate in RCC. ${ }^{31}$ Inhibitors against the active site of TG2, blocking both transamidation and GTP-binding functions by inducing confirmation change, did not interfere with TG2-mediated p53 degradation. This result suggests that interaction of the $\mathrm{N}$ terminal TG2 domain with p53 is essential for TG2's chaperone effect. ${ }^{36}$

Given the role of TG2 as a prometastatic protein in RCC, we aim to determine the relative contribution of the two wellcharacterized (transamidating and GTP-binding) domains of TG2 in oncogenic signaling by investigating complex molecular mechanisms underlying EMT. As there is a positive feedback loop between TGF- $\beta$ and TG $2{ }^{9}$ renal cell adenocarcinoma (RenCa) cell line insensitive to TGF- $\beta$ was chosen as the cell model in order to investigate the role of TG2 in RCC metastatic processes, independently from the TGF- $\beta$ signaling. ${ }^{37}$ Here, we showed that although both TG2-R580A and TG2-W241A mutants induced the expression of EMT markers, only the transamidase-inactive TG2-W241A was able to induce invasiveness and stemness in the mouse RCC cell line RenCa. Conversely, the expression of the GTP-binding deficient-form TG2-R580A and transamidase-deficient form with a low GTP-binding affinity TG2-C277S failed to promote cancer stemness in RenCa cells.

Our data suggest for the first time that GTP-binding activity of TG2 was required to maintain EMT and CSC-related responses in RCC along with cell migration and invasiveness, suggesting that GTP-binding/GTPase activity of TG2 is likely to have a significant prometastatic role for cancer cells to thrive in RCC. These findings support that inhibitors specifically targeting the GTP-binding/GTPase domain of TG2 may serve as a new therapeutic approach in the treatment of mRCC. ${ }^{19}$

\section{RESULTS}

Ectopic Expression of Human TG2 in RenCa Cells. Prometastatic activity of TG2 in RCC remains to be identified at a molecular level. Early work on breast cancer cells ${ }^{19}$ revealed that GTP-binding activity of TG2 is important in the development of metastatic and drug-resistant tumors. Additionally, in the follow-up study, GTP-binding/GTPase activity of TG2 was found to be essential for the genesis and maintenance of epidermal squamous cell carcinoma. ${ }^{23,38}$ In order to understand the possible impact of TG2 enzymatic activities in the complex process of RCC tumor development, mouse RCC cell line RenCa, which is a preferred model cell line for the in vivo studies with a growth pattern that mimics human adult RCC, was transduced with lentiviral vectors encoding wild-type TG2 (wt-TG2), TG2-C277S, TG2-R580A, and TG2-W241A mutants. ${ }^{39}$

The expression of catalytically inactive and GTP-binding defective TG2 constructs in RenCa cells was determined by real-time PCR (RT-PCR). The level of TG2 mRNA (Figure 1A) and protein expression (Figure 1B) showed that all mutants had similar expression patterns. Control experiments investigating the change in the expression of TG2 cell surface binding partners ITGB1 and SDC4 ${ }^{5,7-9}$ demonstrated that the levels of ITG $\beta 1$ and SDC4 were constant in each mutant cell.

Analysis of TG2 cross-linking activity in TG2 mutant expressing RenCa cells confirmed that the GTP-binding defective mutant TG2-R580A exhibited similar transamidase activity to wt-TG2 expressing RenCa cells (Figure 1C). Residual cross-linking activity was detected in cell lysates of both transamidating-defective mutants, TG2-C277S and TG2W241A. 
A
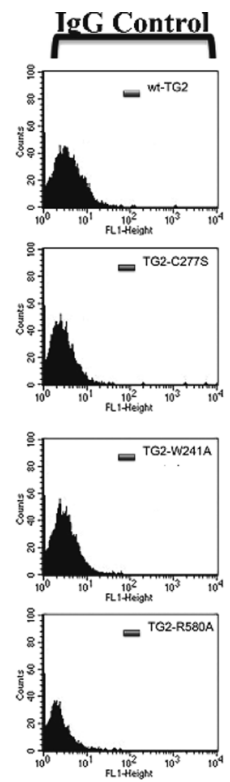

B
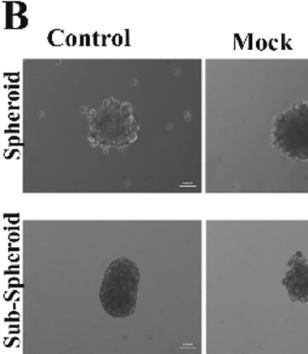
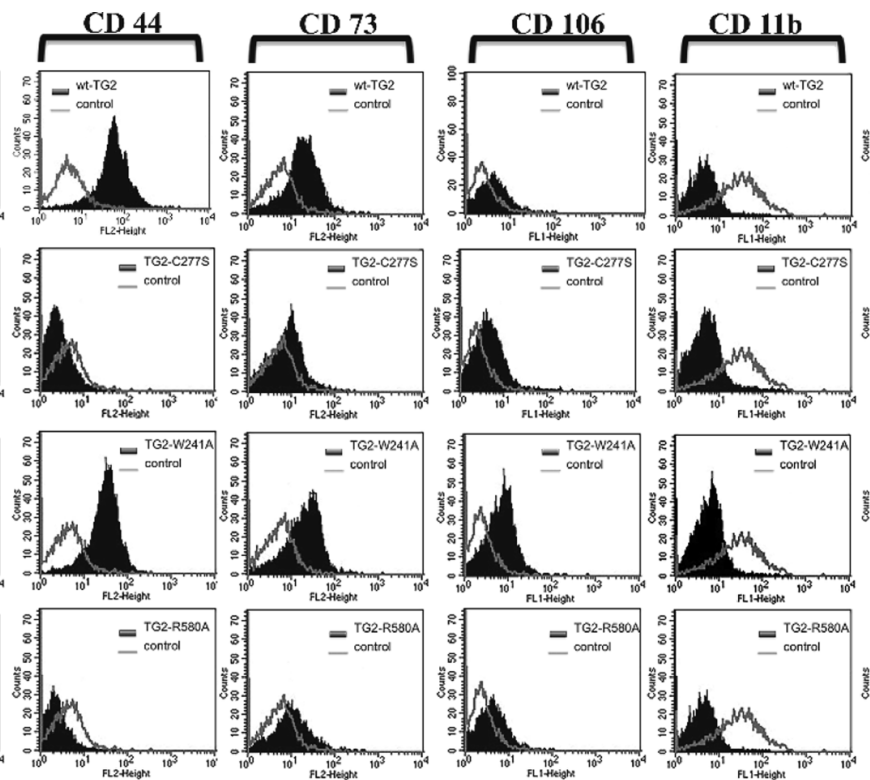

C
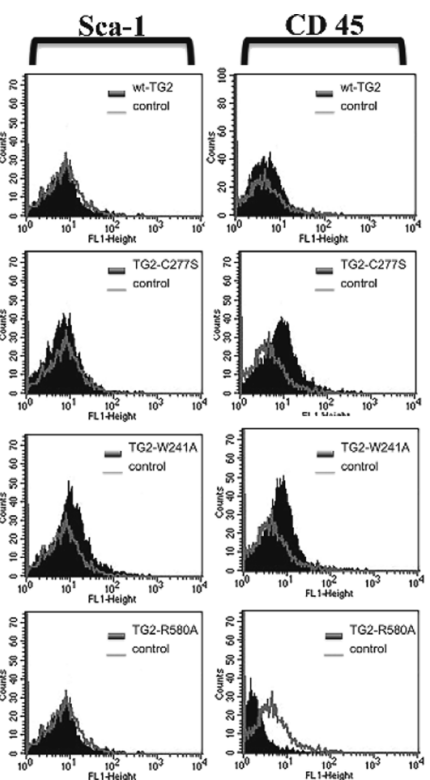
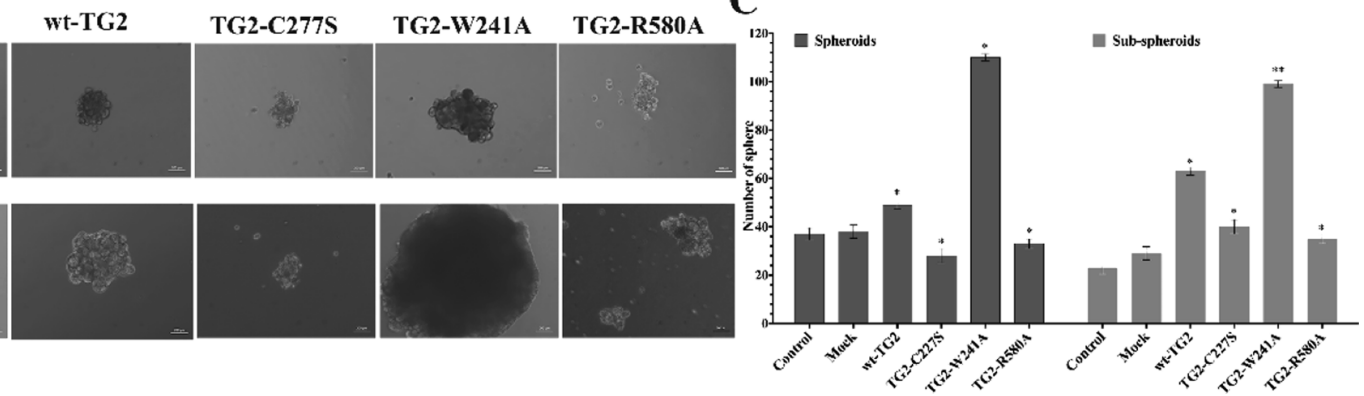

Figure 2. Characterization of transglutaminase 2 constructs in RenCa cells together with their stemness profile. (A) Dark-shaded histograms representing the expression levels in wt-TG2 transduced cells, TG2-C277S transduced cells, TG2-W241A transduced cells, and TG2-R580A transduced cells were either stained by FITC- or PE-conjugated mesenchyme markers. Wild-type control RenCa cells (gray-shaded histograms) were used as the control compared with transduced TG2 constructs to develop the stemness profile. (B) Phase-contrast images of spheroids and subspheroids formed by the indicated TG2 constructs. (C) Quantification analysis of the spheroids and subspheroids formed \pm SD.

\section{Table 1. Percentage Expression Levels for CD Stem Cell Surface Markers ${ }^{a}$}

\begin{tabular}{lcrr} 
CD markers & \multicolumn{1}{c}{ control } & \multicolumn{1}{c}{ wt-TG2 } & \multicolumn{1}{c}{ TG2-C277S } \\
CD44 & $2.39 \pm 0.91$ & $87.07 \pm 1.34$ & $0.49 \pm 0.35$ \\
CD73 & $21.64 \pm 13$ & $59.47 \pm 3.09$ & $25.92 \pm 6.97$ \\
CD106 & $0.28 \pm 0.47$ & $1.8 \pm 0.44$ & $2.89 \pm 0.86$ \\
CD11b & $28.67 \pm 0.09$ & $2.94 \pm 0.64$ & $1.71 \pm 1.14$ \\
Sca-1 & $19.40 \pm 3.69$ & $19.09 \pm 4.92$ & $19.70 \pm 0.75$ \\
CD45 & $1.86 \pm 1.18$ & $3.33 \pm 1.48$ & $8.78 \pm 2.41$
\end{tabular}

$\begin{aligned} & \text { TG2-W241A } \\ & 91.57 \pm 3.31 \\ & 60.36 \pm 1.46 \\ & 3.73 \pm 0.04 \\ & 14.88 \pm 5.60 \\ & 20.10 \pm 1.39 \\ & 9.11 \pm 1.83\end{aligned}$

TG2-R580A

$0.59 \pm 0.15$

$38.19 \pm 7.8$

$2.27 \pm 1.64$

$1.35 \pm 1.18$

$18.56 \pm 2$

$0.23 \pm 0.09$

${ }^{a}$ Each values represent the average of three experiments \pm SD performed independently.

GTP-Binding Function of TG2 Is Essential for Renal Cancer Cell Stemness. Given that TG2 has been shown to transform healthy mammary epithelial cells by promoting CSC properties and mammosphere formation, ${ }^{19}$ we first evaluated the role of TG2 in the development of the CSC phenotype in RenCa cells stably expressing wt-TG2 and its mutants by flow cytometry analysis of mesenchymal markers and spheroid assay (Figure 2).

Recent studies indicate that CD44 plays an important role in the promotion of cell invasion and tumor metastasis. ${ }^{40,41}$ Analysis of CD44 expression in RenCa cells demonstrated that expression of wt-TG2 and TG2-W241A induced the formation of a CD $44^{\text {high }}$ cell population. In addition, wt-TG2 and TG2W241A expression was also associated with a considerable increase in the number of CD73 expressing RenCa cells (Figure 2A). No detectable change was observed in CD106 and $\mathrm{CD} 11 \mathrm{~b}$ surface markers because of the expression of wt and mutant TG2 constructs in RenCa cells. RenCa cells expressing TG2 mutant constructs were negative for the hematopoietic markers Sca-1 and CD45 (Table 1).

Previous studies indicated that cancer cells positive for $\mathrm{CD}$ stem cell markers possess the ability to form $3 \mathrm{D}$ spheroids under the low-attachment conditions. ${ }^{42,43}$ To determine whether TG2 expression in RenCa cells induce the selfrenewal ability to form renal spheroids, we have performed spheroid and subspheroid in vitro assays (Figure 2B). Control RenCa cells possessed sphere-forming ability with a low efficiency. Expression of TG2-C277S and TG2-R580A 


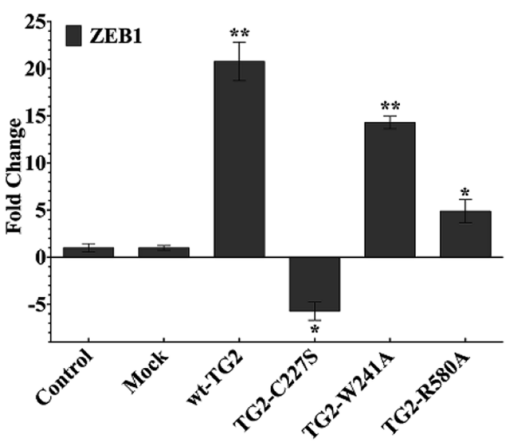

D

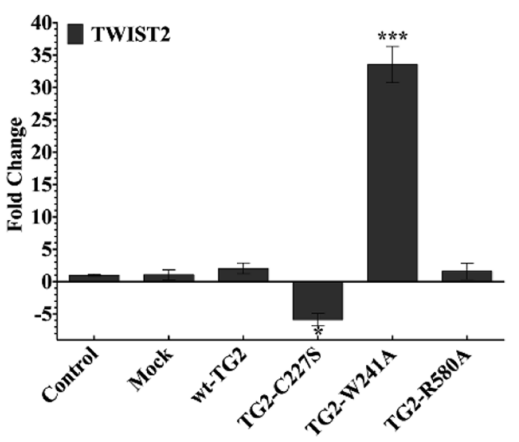

B

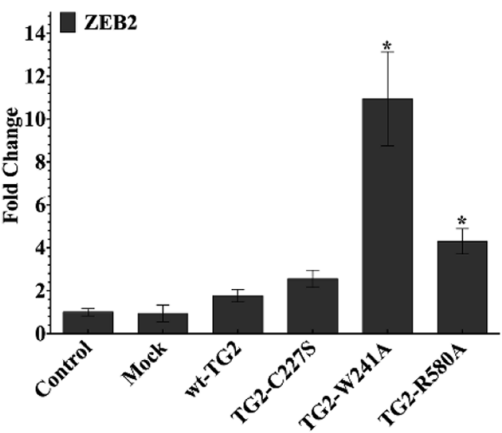

$\mathbf{E}$

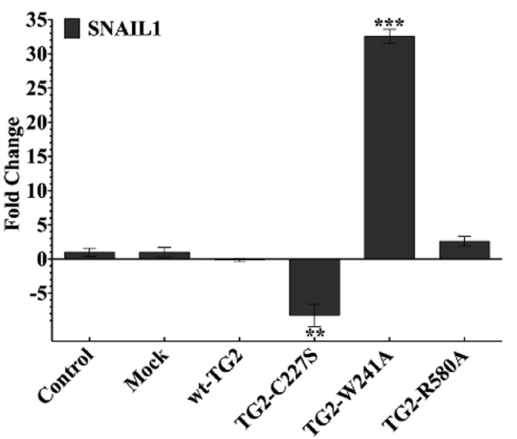

C

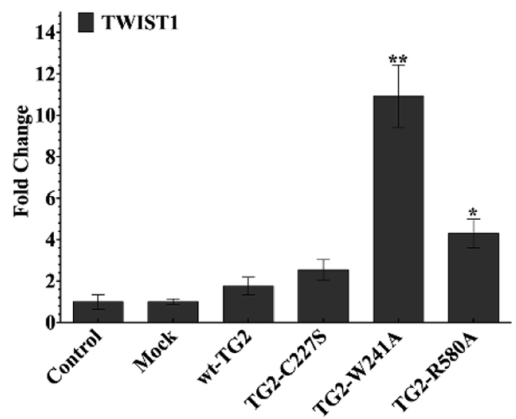

$\mathbf{F}$

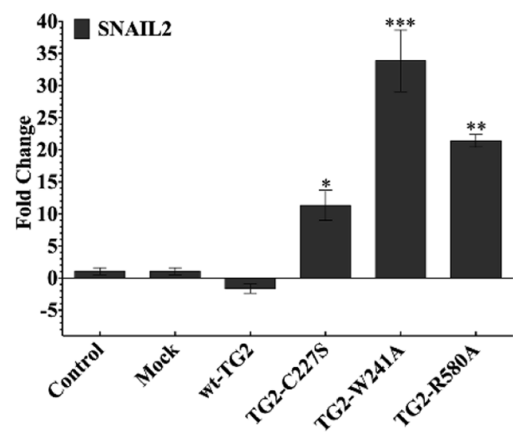

Figure 3. GTP-binding activity of transglutaminase 2 is important for epithelial to mesenchymal transition. RT-PCR analysis showing the changes in the expression levels of EMT-related transcription factors in RenCa cells transduced with TG2 constructs (wt-TG2, TG2-C277S, TG2-W241A, and TG2-R580A), 18S mRNA used as the housekeeping gene. (A) Zeb-1, (B) Zeb-2, (C) Twist-1, (D) Twist-2, (E) Snail-1, and (F) Snail-2 data values represent the average of three independent experiments (mean $\pm S D$ ).

constructs did not significantly increase the number of spheroids formed, when compared to the control RenCa cells. However, wt-TG2 and TG2-W241A mutant cells exhibited a respective 1.3- and 2.9-fold significant increase in the spheroid number, compared to the control RenCa cells (Figure 2C). Similar results were obtained in subspheroid experiments except for TG2-C277S cells as they showed an increased ability to form subspheroids by 1.5 -fold. Taken together, these data indicate that GTP-binding/GTPase ability of TG2 is necessary for stem cell character and anchorageindependent self-renewal.

Importance of Catalytic and GTP-Binding/GTPase Activity of TG2 for the Activation of EMT. Recent studies indicate that TG2 expression is associated with the upregulation of EMT transcription factors including Zeb 1/2, Twist $1 / 2$, and Snail $1 / 2$ in breast $^{44,45}$ and ovarian cancer cell lines. ${ }^{46}$ Therefore, we next seek to investigate whether the GTP-binding/GTPase domain of TG2 is crucial for the upregulation of EMT transcriptional factors.

Analysis of expression levels for EMT regulators showed that wt-TG2 cells increased Zeb1 mRNA levels 20.8-fold, while TG2-W241A and TG2-R580A expression in RenCa cells led to a respective 14- and 5-fold increase in Zeb1 levels when compared to the control cells (Figure 3A). Interestingly, a 5.7fold decrease in Zeb1 levels was detected for TG2-C277S cells. No significant change was found in Zeb2 mRNA levels except for the 11- and 4.3-fold increase recorded for TG2-W241A and TG2-R580A cells (Figure 3B).
Similarly, the expression of TG2-W241A construct led to an 11-fold upregulation in Twist 1, while TG2-R580A cells exhibited a $\sim 4$-fold increase in Twist 1 mRNA level in comparison to the control RenCa cells. TG2-C227S cells showed a $\sim 3$-fold increase in Twist 1 (Figure 3C). A significant 34-fold increase in Twist 2 was observed for TG2-W241A, whereas no significant change in Twist 2 was observed for TG2-R580A compared to the control RenCa cells. TG2C277S expression in RenCa cells led to a 5-fold downregulation in Twist 2 (Figure 3D). Expression of wt-TG2 and TG2-C277S resulted in decreased Snail1 levels, whereas TG2W241A expression in RenCa cells induced a 32.5-fold increase in Snail1 mRNA, respectively (Figure 3E). Figure 3F shows that TG2-C277S, TG2-W241A, and TG2-R580A cells exhibited 11-, 33-, and 21-fold increased Snail2 expression. Overall, these results suggest that the GTP-binding/GTPase activity of TG2 might be more potent than its transamidation activity in the induction of EMT.

Role of Transamidase Activity and GTP-Binding of TG2 in RCC Cell Migration. Recent studies indicate that tumor cells that upregulate molecular markers of EMT also exhibit an enhanced migration potential. ${ }^{47,48}$ Upon EMT transactivation, adherent junctions are disrupted because of a switch in the cell-cell adhesion protein E-cadherin to $\mathrm{N}$ cadherin, followed by the induction of migratory phase due to increased vimentin expression. ${ }^{49}$ To understand the role of TG2-functional activities in the cell motility, the ability of TG2 mutant RenCa cells to detach from the colonies and spread to near vicinity was tested using the scatter assay (Figure 4A). 
A 0

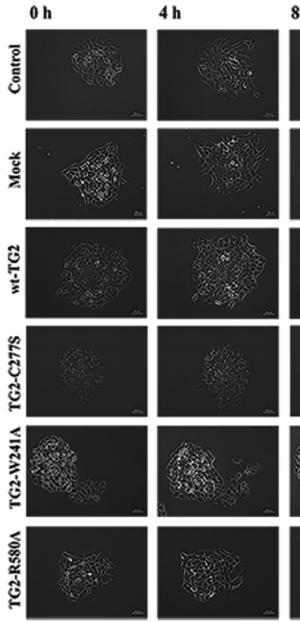

C

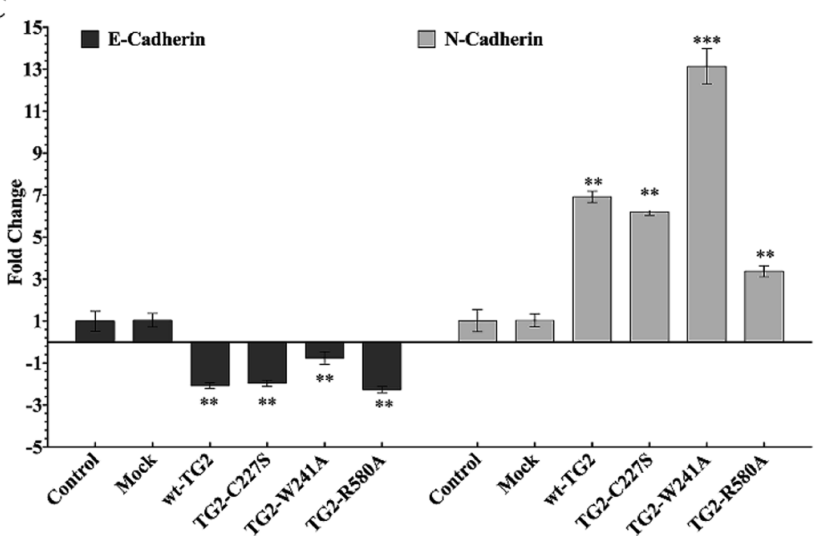

B

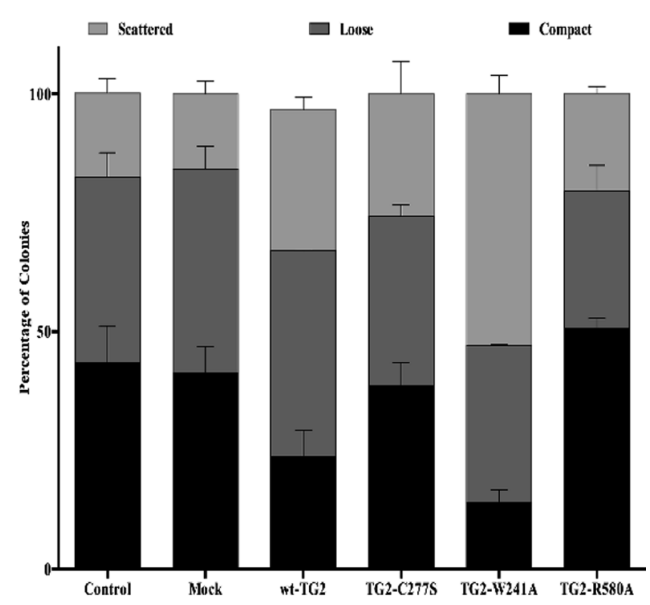

D

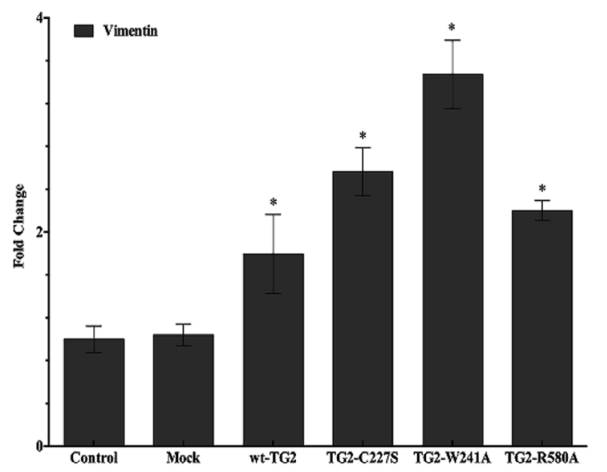

Figure 4. GTP-binding activity, rather than transamidase activity of transglutaminase 2 is associated with the cell migration and EMT. (A) Cell migration potential of RenCa cells transduced with TG2 constructs (wt-TG2, TG2-C277S, TG2-W241A, and TG2-R580A) monitored using scattering assay. Images were taken at $0-24 \mathrm{~h}$ after the colony formation under a light microscope at $20 \times$ objective. Similar results were observed in triplicate. Bars $200 \mu \mathrm{m}$. (B) Percentages of each form of the colonies (scattered, loose, and compact) analyzed from three independent experiments (mean $\pm \mathrm{SD}$ ). (C). RT-PCR analysis showing the downregulated E-cadherin and upregulated $\mathrm{N}$-cadherin expression levels. (D) RT-PCR analysis showing the vimentin expression of RenCa cells transduced with TG2 constructs. 18S mRNA was used as a housekeeping gene to normalize the mRNA levels. Data values represent the average of three independent experiments (mean $\pm S D$ ).

Our findings indicate that control cells together with TG2C277S and TG2-R580A cells demonstrated a similar migration pattern with $45 \%$ compact, $35 \%$ loose, and $20 \%$ scattered colonies. RenCa cells expressing wt-TG2 and TG2-W241A cells formed, on average, $15 \%$ less compact colonies and $20 \%$ more scattered colonies than the control cells (Figure 4B, Video S1).

Analysis of expression levels of $E$-cadherin and $N$-cadherin indicates that wt-TG2, TG2-C277S, TG2-W241A, and TG2R580A mutant cells showed relatively 2-, 1.9-, 0.8-, and 2.2fold decreased levels of $E$-cadherin expression when compared to the control RenCa cells. Expression of wt-TG2, TG2C277S, TG2-W241A, and TG2-R580A, respectively, resulted in 7-, 6.2-, 13-, and 3.4-fold increase in $\mathrm{N}$-cadherin (Figure 4C). Similar to cadherin switch, the upregulation of vimentin expression associated with the preliminary preparation of cells to the migratory process was also evident in TG2 mutant RenCa cells. Vimentin expression was increased by 1.8 -fold in wt-TG2, 2.5-fold in TG2-C277S, 3.4-fold in TG2-W241A, and 2.2-fold in TG2-R580A cells in comparison to control RenCa cells (Figure 4D). These data suggest that although TG2 expression is sufficient to trigger the cadherin switch and increase the vimentin expression, GTP-binding/GTPase activity is predominantly effective to drive the cell-cell dissociation process, resulting in subsequent migration as individual cells.

GTP-Binding Activity of TG2 Is Essential for Matrix Metalloproteinase Upregulation and the Invasive Phenotype. Metastasis of primary tumors to distant sites is a multistep process that involves the upregulation of matrix metalloproteinase (MMP) activities necessary for the invasion, intravasation, extravasation, and lastly, metastatic colonization. ${ }^{50}$ In this context, changes in gelatinase and collagenase expression levels were explored in TG2 activity variants by RTPCR. MMP1a mRNA levels was increased by 7.5 -fold in parallel with the stable wt-TG2 expression, albeit a 14-fold increase was detected for TG2-W241A cells when compared to the control RenCa cells (Figure 5A). wt-TG2 and TG2W241A transduction of RenCa cells also promoted 11 and 15 times more MMP2 expression than the control, respectively, while only 6-fold increase was detected for TG2-C277S and TG2-R580A cells (Figure 5B). MMP3 expression was increased by 4.3 -fold in wt-TG2, 2.6-fold in TG2-C277S, 6.4-fold in TG2-W241A, and 1.6-fold in TG2-R580A cells in comparison to control RenCa (Figure 5C). Likewise, only TG2-W241A cells displayed a significant upregulation in MMP9 mRNA levels (Figure 5D). Interestingly, stable expression of wt-TG2 in RenCa cells led to 15-fold increase 
A

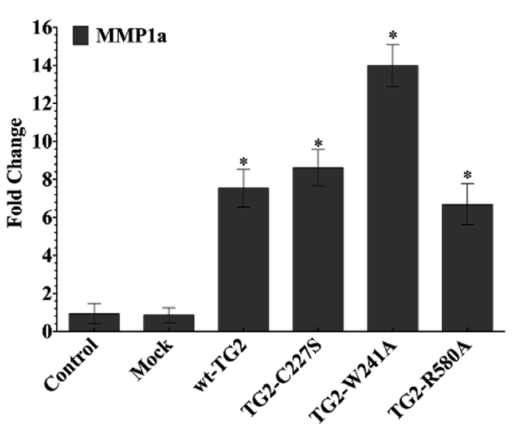

D

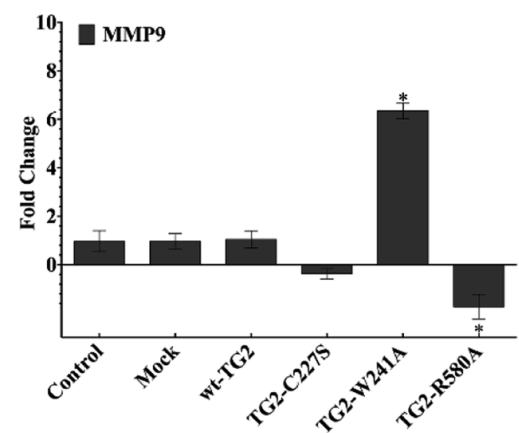

B

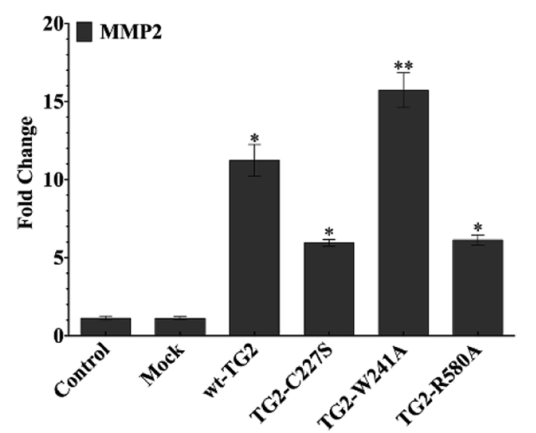

C

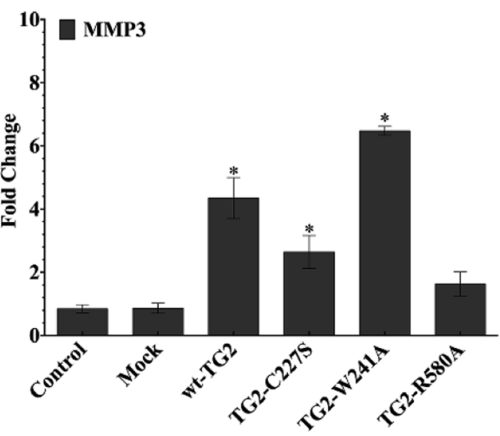

$\mathbf{E}$

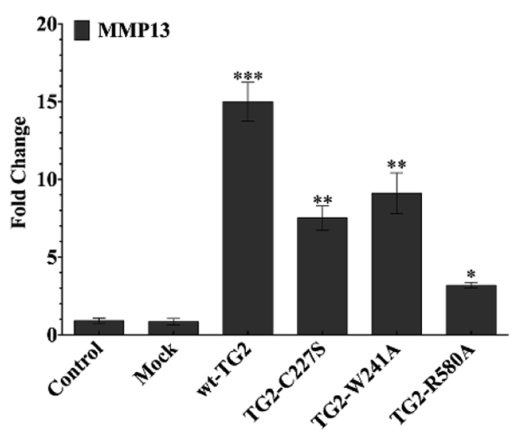

Figure 5. Upregulation of MMPs levels correlates with the migration and progression of the aggressive phenotype. RT-PCR analysis of MMP's in RenCa cells transduced with TG2 constructs (wt-TG2, TG2-C277S, TG2-W241A, and TG2-R580A), 18S mRNA was used to normalize the mRNA levels. (A) MMP-1a, (B) MMP-2, (C) MMP-3, (D) MMP-9, and (E) MMP-13 data values represent the average of three independent experiments $($ mean $\pm \mathrm{SD})$.

in the levels of MMP13 mRNA, while the expression of TG2 mutants only led to an average of 6 -fold increase in that of MMP13 mRNA (Figure 5E). Overall, our results suggests that although TG2 as a protein has the ability to increase MMP expression, GTP-binding/GTPase activity (TG2-wt and TG2W241A) was shown to potentiate the MMP upregulation.

Intra- and extravasation ability of TG2-constructed mutants was elucidated by the Matrigel transwell assay. Figure 6A shows that cell expression of TG2-W241A promoted the invasive phenotype in RenCa cells. In that, the number of invasive cells was four fold higher in TG2-W241A cells compared to the control, wt-TG2, TG2-C277S, and TG2R580A cells (Figure 6B). These results further conclude that catalytically inactive yet GTP-binding/GTPase active TG2W241A cells had remarkably high invasive potential associated with the upregulation of MMP biosynthesis.

\section{DISCUSSION}

Accumulating evidence showed that mRCC is one of the most resistant and highly vascular malignancy among the other types of kidney cancers with a poor survival outcome. ${ }^{32,51}$ Because of the dramatic increase in mRCC incidence in recent years, studies focused on the identifications of novel oncogenes and molecular pathways that could serve as therapeutic targets in mRCC. ${ }^{52,53}$ One such molecular target could be TG2 as its upregulated expression was prevalent not only in $\operatorname{mRCC}^{32,51,54}$ but also in other highly aggressive, metastatic, and treatmentresistant types of human cancers including glioblastoma, ${ }^{55}$ breast, ${ }^{10,45,56,57}$ ovarian, ${ }^{20,58,59}$ and pancreas. ${ }^{.0}$ Several studies have indicated that silencing of TG2 or using TG2 inhibitors often reduces the acquired metastatic phenotype in the cancer cells. ${ }^{3,61}$ In addition, previous studies showed that the relevance of TG2 to cancer progression may vary upon the type of cancer together with its stage and the location. ${ }^{62}$ In order to explain how TG2 contributes to the cancer progression, recent studies focused on the role of catalytic and GTP-binding/GTPase domains of TG2 in breast, epidermoid, epidermal squamous, and ovarian cancer progression, with particular emphasis on EMT..$^{19,21-23,63,64}$ In line with these studies, here, we investigated whether either or both GTPase and transamidase functions of TG2 contribute to the stem cell maintenance, EMT, cell migration, and invasion processes necessary for $\mathrm{mRCC}$ progression.

Considering the crucial interrelation between TG2 and its cell surface binding partners (ITG $\beta 1$ and SDC4) in the tumor progression ${ }^{6,7,9,13,32,65}$ we first showed that the exogenous expression of TG2 mutants in RenCa cells did not change the expression levels of ITG $\beta 1$ and SDC4. We next demonstrated that the GTP-binding/GTPase function of TG2 was required to promote the stemness profile and maintain renospheres in RenCa cells, which was in agreement with the studies showing that GTP-binding/GTPase activity of TG2 was necessary for inducing EMT-CSC in breast ${ }^{19}$ and epidermal squamous carcinoma. ${ }^{23,38}$ Interestingly, GTP-binding inhibitors was recently shown not to interfere with the proliferation ACHN RCC cell line. ${ }^{36}$ The fact that GTP-binding/GTPase activity of TG2 was essential for the anchorage-independent proliferation of RenCa cells can be explained by the previous report ${ }^{66}$ showing the transamidase-independent activation of the PI3K/ $\mathrm{mTOR}$ and PI3K/SRC pathway though protein-protein interaction of TG2 with PI3K and SRC kinase. It is possible that the R580A transamidase-deficient form might interfere 
A
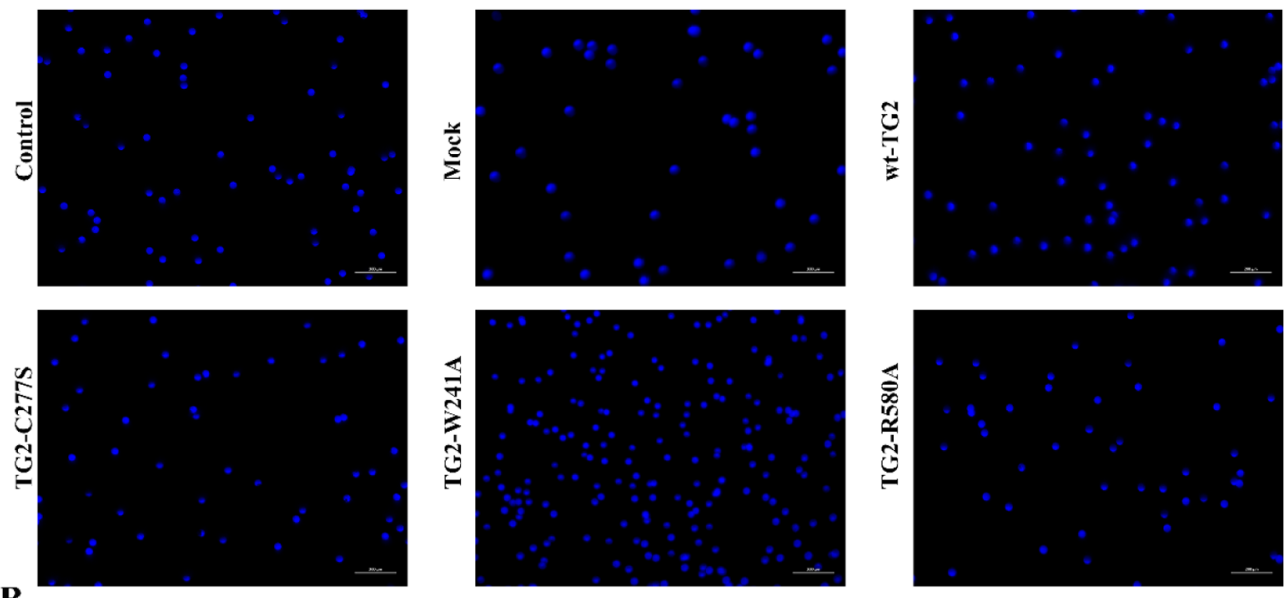

B

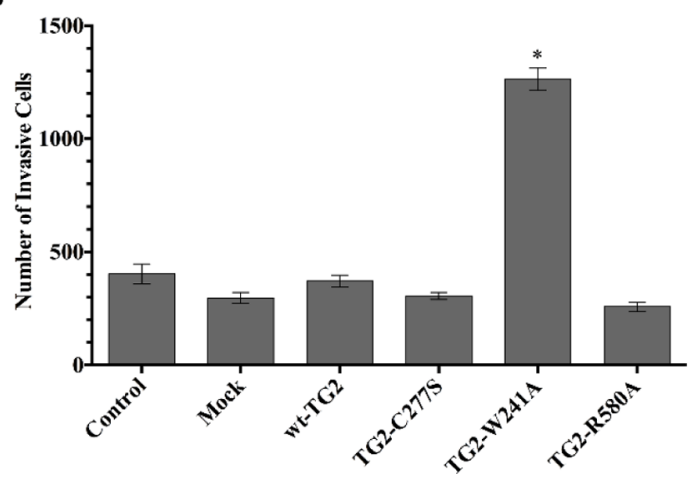

Figure 6. GTP-binding activity is more important than transamidase activity for the invasive potential. (A) Cell invasion potential of RenCa mutants was analyzed by the Matrigel transwell assay. Nuclei of cells migrating to the bottom of the well were stained with DAPI, and images were captured using a fluorescence microscope from five nonoverlapping fields. Bars $200 \mu \mathrm{m}$. (B) Images were analyzed using Scion Image software. Each data point represents mean for number of invasive cells \pm SD from three independent experiments.

with TG2's ability to induce the formation of P3IK-activating complex and hence hinder the anchorage-dependent proliferation capacity of RenCa cells.

Given that TG2-mediated TGF- $\beta$ activation leads to the induction of NF- $\kappa \mathrm{B}$, which plays a major role in the regulation of EMT and cell migration during mRCC progression, ${ }^{67}$ further insight into the role of TG2 functional domains in the absence of the TGF- $\beta$ signaling pathway was assessed using RenCa cells that lack the functional TGF- $\beta$ receptor II. ${ }^{37}$

EMT is a complex dynamic developmental program that is often activated during the cancer progression including invasion and metastasis. ${ }^{68,69}$ Recent studies indicated that $\mathrm{NF}-\kappa \mathrm{B}$ activation is necessary for EMT, cancer cell metastasis, and drug resistance. ${ }^{70,71}$ The trigger for the molecular switch of the EMT program was associated with the changes in the expression patterns of transcription factors such as Zeb1/Zeb2, Twist1/Twist2, and Snail1/Snail2. Although previous studies suggested a strong link between TG2 expression and EMT induction in various malignant neoplasms of epithelial origin, ${ }^{18,21,22,64,72}$ molecular mechanisms defining the involvement of TG2 in the EMT process has not been well elucidated. TG2 was shown to be necessary for the expression of EMT markers as the TG2 knockdown or treatment with TG2 inhibitors resulted in the reduced expression levels of EMT markers in breast and squamous cell carcinoma. ${ }^{73,74}$ In the present study, we investigated the role of catalytic and functional GTP-binding/GTPase domains of TG2 in regulating RCC EMT. Our results indicated significant increases in the mRNA expression levels of all EMT-inducing transcription factors for TG2-W241A expressing RenCa cells, while the transamidase-active TG2 protein could also potentiate Zeb-1 and Snail-2, suggesting that GTP binding/GTPase was required for full throttle induction of the EMT process in RCC. Accordingly, in previous reports, it has also been demonstrated that GTP binding/GTPase of TG2 drives the EMT process in breast ${ }^{19}$ and epidermoid ${ }^{23,38}$ cancers.

Tumor cells having undergone the $E$ - to $N$-cadherin switching process together with elevated EMT markers resulted in an enhanced migratory potential. ${ }^{48,49}$ Recently, it was shown that the aberrant expression of TG2 was associated with cadherin switch in various epithelial cancers. ${ }^{18,74,75}$ Here, we demonstrated that the expression of either the wt or mutant form of TG2 was enough for the initiation of cadherin switch and increase in the expression level of vimentin in RenCa cells, suggesting that TG2 might exert its effect through proteinprotein interactions. ${ }^{21}$ Given that $E$ - to $N$-cadherin switch is associated with the initial steps of EMT programming, the role of TG2 functional activities in the cell motility was investigated by monitoring the ability of TG2-expressing mutant RenCa cells to detach from colonies and spread to distant vicinity using the scatter assay. The fact that compact colonies formed by TG2-R580A RenCa cells fail to scatter implicated that the GTP-binding/GTPase domain of TG2 may be essential in the cell-cell dissociation in RCC. In the natural course of events, the cell dispersal from the main tumor body, followed by the cell invasion process which involves phenotypic switch and 
change in the ECM dynamics through the MMP activation. ${ }^{28}$ Evidence showed that the TG2 overexpression led to an elevation in the expression level of MMPs including MMP $1,{ }^{76}$ MMP2, ${ }^{77} \mathrm{MMP}^{19}{ }^{19}$ and MMP9 ${ }^{22,76}$ in epidermoid, ovarian, and breast cancers. In agreement with aforementioned studies, wt-TG2 and TG2-W241A expressing RenCa cells displayed increased mRNA levels of MMPs: MMP1a, MMP-2, MMP-3, MMP-9, and MMP-13. In wt-TG2 and TG2-W241A cells, the increased MMP expression was associated with an increased invasive capacity based on the higher number of invasive/ migratory cell count when compared to other TG2 RenCa mutants. These results indicated that TG2-induced MMP expression associated with the invasiveness of mRCC was dependent on the enzyme's GTP-binding/GTPase ability rather than the transamidation activity. Previously, we showed that TG2 transamidating activity was downregulated in primary RCC tumors ${ }^{78}$ to favor tumor growth by ECM destabilization. The fact that wt-TG2 possesses not only GTPbinding/GTPase activity but also transamidating activity explains the reduced metastatic activity in wt-TG2 expressing RenCa when compared to TG2-W241A cells. In spite of induction of some EMT markers, the presence of catalytically active TG2 in the tumor microenvironment reduces the tumor growth and invasion because of increase in the ECM deposition and cross-linking, leading to ECM-stiffening. ${ }^{79}$

\section{CONCLUSIONS}

Overall, our findings demonstrated that previously reported prometastatic function of TG2 $2^{32,33,51}$ in mRCC mostly relies on the GTP-binding/GTPase activity of the enzyme by inducing cancer stemness and EMT and cell migration/ invasion. Recent reports suggest that TG2 was responsible for the activation of FAK and its downstream PI3K/AKT and NF$\kappa \mathrm{B}$ pathways in cancer cells. ${ }^{14,60}$ Given that GTP-binding/ GTPase activity of TG2 was recently implicated in SRCdependent activation of PI $3 \mathrm{~K}^{80}$ and in CSC survival, ${ }^{38}$ TG2 in closed/GTP-bound conformation might contribute to the mRCC by acting as a scaffold protein in the FAK and PI3K/ AKT axis. Our results raise the likelihood for the use of TG2 GTP-binding/GTPase-site-specific inhibitors as novel therapeutics in the treatment of advanced RCC.

\section{EXPERIMENTAL PROCEDURES}

Reagents and Antibodies. For spheroid and subspheroid assays, growth supplements were used: B27 supplement $(50 \times)$ (Gibco, 15504-044), fibroblast-growth factor $(100 \mu \mathrm{g} / \mathrm{mL})$ (Gibco, AA-10-155), insulin transferrin selenium (ITS) (Gibco, 41400-045), N2 supplement (100×) (Gibco, 17502$048)$, and epithelial-growth factor (EGF) $(200 \mu \mathrm{g} / \mathrm{mL})$ (Invitrogen, PHG0313); mouse-anti-TG2 antibody (CUB 7402, Thermo Fisher Scientific, M S-224-P), monoclonal mouse anti-ITG $\beta 1$ antibody (Santa Cruz, sc-8978), and antiSDC-4 antibody (Abcam, ab24511). For characterization, antimouse CD11b (BioLegend, B192967), antimouse Sca-1 (BioLegend, B163257), antimouse CD44 (BioLegend, B193068), antimouse CD45 (BioLegend, B187805), antimouse CD73 (BioLegend, B182619), antimouse CD29 (BioLegend, B181560), and antimouse CD106 (BioLegend, B178443). Antirabbit IgG peroxidase (A0545) and antimouse IgG peroxidase (A4416) conjugates were purchased from Sigma.
Cell Line. RenCa were maintained in RPMI-1640 (Gibco, BE12-702F) growth medium supplemented with $10 \%(\mathrm{v} / \mathrm{v})$ fetal bovine serum (FBS) (Sigma, F9665) and 100 units $/ \mathrm{mL}$ penicillin, $100 \mu \mathrm{g} / \mathrm{mL}$ streptomycin (Sigma, 6SLBJ7114U). wtTG2 cDNA (coding 224Val) was subcloned into the pENTR1A no CCDB (w48-1) vector (gift from Eric Campeau; ${ }^{81}$ Addgene \#17398) at the EcoRI position, and mutants were generated based on QuikChange site-directed mutagenesis kit protocol (Stratagene). The restriction digestion and sequencing confirmed constructs were recombined into a pLenti CMV Blast DEST (706-1) destination vector, which was a gift from Eric Campeau, ${ }^{35}$ (Addgene \#17451) using LR Clonase and GATEWAY technology based on the manufacturer protocol (Thermo \#11791020).

TG2-Mutant Constructs Lentivirus Production and Transduction. The packaging vectors (psPAX2 and $\mathrm{pMD} 2 \mathrm{G}$ ) were a gift from Didier Trono (Addgene \#12260 and \#12259, respectively). Lentiviral particles were produced using HEK293FT cells (Invitrogen) maintained in Dulbecco's modified Eagle's medium (Gibco, 41966) and transfected by the calcium phosphate coprecipitation method. In brief, cell monolayers treated with $2.5 \mathrm{mM} \mathrm{CaCl} 2$ dissolved in $\mathrm{HBSS}$ were incubated with $20 \mu \mathrm{g}$ of pLenti CMV Blast TG2 DNA together with packaging plasmids for $16 \mathrm{~h}$. Then, fresh medium was added. and viral particle-containing cell media were collected twice after 24 and $48 \mathrm{~h}$. The virus containing supernatants were centrifuged, filtered, and mixed before aliquoting for storage/freezing. RenCa cells seeded at $3 \times 10^{4}$ density were pretreated with $8 \mu \mathrm{g} / \mathrm{mL}$ of polybrene for $2 \mathrm{~h}$ and then incubated with lentiviral particles overnight at $37^{\circ} \mathrm{C}$. Cell selection was performed using $6 \mu \mathrm{g} / \mathrm{mL}$ blasticidin-containing growth medium RPMI 1640.

Flow Cytometry. CD marker analysis was performed as described previously. ${ }^{82}$ In brief, cells fixed with $4 \%$ paraformaldehyde were incubated with FITC- or PEconjugated antibodies (CD44, CD73, CD106, CD11b, Sca-1, and $\mathrm{CD} 45$ ) for $1 \mathrm{~h}$ at room temperature. Following two sets of washes with PBS, the mesenchymal stem cell marker expression profile was determined using a Becton Dickinson FACSCalibur flow cytometer, and the data were analyzed with the CellQuest Pro program.

Spheroid Formation Assay. RenCa cells resuspended in RPMI 1640 medium supplemented with 2\% B27 serum-free supplement, $1 \% \mathrm{~N} 2,20 \mathrm{ng} / \mathrm{mL}$ EGF, $10 \mathrm{ng} / \mathrm{mL}$ FGF, $1 \times \mathrm{ITS}$, and $0.5 \%$ methylcellulose (spheroid medium) were plated in Costar 24-well ultralow flat-bottom attachment plates (Corning-Costar, CLS 3473) at $2.5 \times 10^{2} /$ well density. Spheroid size and colony numbers were surveyed every $24 \mathrm{~h}$, and images were taken for spheres larger than $50 \mu \mathrm{m}$ using a Carl Zeiss Primovert microscope equipped with a camera system Axiocam 105 digital color microscope. After 15-20 days, in order to investigate the self-renewing potential of the cells, spheres of the first generation were collected, trypsinized, resuspended in spheroid medium, and then seeded into 24-well ultralow flat-bottom attachment plates at 25 cells/well density. Subspheroid size and colony numbers were surveyed every 24 $\mathrm{h}$ as described above. The spheroid growth was counted from multiple wells, and efficiency of the sphere formation was calculated in percentage as the mean \pm standard deviation (SD) from at least three independent experiments.

Expression Analysis Using Quantitative PCR and Western Blotting. Total RNA isolation was performed as described $^{9}$ using the same PCR conditions and QuantiTect 
Primer assay for hTGM2 (202689401), Zeb-1 (174899188), Zeb-2 (174899189), Snail-1 (174899193), Snail-2 (174899190), Twist-1 (174899194), Twist-2 (174899191), 18 S RNA, MMP-1a (208679791), MMP-2 (208679792), MMP-3 (208679793), MMP-9 (208679794), MMP-13 (208810906), E-cadherin (202689402), N-cadherin (202689403), and vimentin (208810905). The protein expression was analyzed by western blotting following the protocol in Telci et al. ${ }^{7}$ In brief, the cell lysate was resolved either in 8 or $12 \%$ SDS-PAGE and transferred onto nitrocellulose membranes, which were then probed with antimouse TG2 CUB 7402, antirabbit SDC-4, or antimouse ITG $\beta 1$. $\beta$-Actin was used as an internal control to confirm the equal loading.

TG2 Activity Assay. In vitro TG2 activity assay was performed using TG2-CovTest-specific colorimetric microassay kit (CovaLab), as described previously ${ }^{83}$ according to manufacturer's instructions. In brief, cells were lysed using three rounds of freeze-thaw cycle, and $100 \mu \mathrm{g}$ of the protein from each sample was incubated in the reaction mixture containing biotinylated T26 peptide (amine-acceptor/acyldonor) in a 96-well plate, which was precoated by spermine (amine-donor/acyl-acceptor) at $37{ }^{\circ} \mathrm{C}$ for $30 \mathrm{~min}$. Reaction was visualized with the addition of the enzyme tracer streptavidin-labeled horseradish peroxidase, and the optical density of each well was measured at $450 \mathrm{~nm}$ using a spectrometer.

Scattering Assay. RenCa cells $\left(1 \times 10^{3}\right)$ plated into sixwell plates in RPMI-1640 growth medium were allowed to grow as colonies. Upon colony formation, growth medium was replaced with AIM-V (Gibco, 12055-091) medium, and cell scattering from seven selected colonies was monitored at 4, 8, 12, and $24 \mathrm{~h}$ with a Carl Zeiss Primovert microscope equipped with a camera system Axiocam 105 digital color under a $20 \times$ objective. For data analysis, colonies in three different (scattered, loose, and compact) forms were counted and expressed as the mean percentage \pm SD from at least three independent experiments.

Transwell-Invasion Assay. Cell invasion assay was performed using $8.0 \mu \mathrm{m}$ pore size $\mathrm{BD}$ BioCoat inserts (Costar 353097). Cells in AIM-V medium were seeded on the upper chambers of Matrigel-coated transwell inserts at $2 \times 104$ cells/ chamber density; RPMI containing 10\% FBS was placed in the lower chamber. Cells were allowed to migrate for $24 \mathrm{~h}$, and nonmigrant cells were gently removed from the upper chamber using a cotton swab. Following fixation with $4 \%$ paraformaldehyde, cells were stained with DAPI. Using $10 \times$ magnification, five images from nonoverlapping fields were captured using a Carl Zeiss fluorescence microscope equipped with acamera system Axiocam 105 digital color, and the total number of the cells/well was evaluated using the Scion Image Analysis Program. Cell number per sample was expressed as the mean \pm SD from at least three independent experiments.

Statistical Analysis. All values presented are the mean \pm SE (standard error) from triplicate experiments unless otherwise stated. Comparisons between groups were done according to parametric statistics using the Student's $t$-test for the parametric and Mann-Whitney test for the nonparametric distribution in GraphPad Prism version 6.0 (GraphPad Software, San Diego, California, USA). ${ }^{*} p$-values $<0.05$, $* * p$-value $<0.01$ and $* * * p$-value $<0.001$ considered as statistically significant.

\section{ASSOCIATED CONTENT}

\section{Supporting Information}

The Supporting Information is available free of charge at https://pubs.acs.org/doi/10.1021/acsomega.0c04226.

Cell scattering analysis of control nontransduced RenCa by time-lapse video (ZIP)

Cell scattering analysis of wt-TG2 by time-lapse video (ZIP)

Cell scattering analysis of TG2-C277S by time-lapse video (ZIP)

Cell scattering analysis of TG2-W241A by time-lapse video (ZIP)

Cell scattering analysis of TG2-R580A by time-lapse video (ZIP)

\section{AUTHOR INFORMATION}

\section{Corresponding Author}

Dilek Telci - Department of Genetics and Bioengineering, Yeditepe University, Istanbul 34755, Turkey; 이이.org/ 0000-0002-2793-6533; Email: dilek.telci@yeditepe.edu.tr

\section{Authors}

Burge Ulukan - Department of Genetics and Bioengineering, Yeditepe University, Istanbul 34755, Turkey

Ajna Bihorac - Department of Genetics and Bioengineering, Yeditepe University, Istanbul 34755, Turkey

Tarik Sipahioglu - Department of Genetics and Bioengineering, Yeditepe University, Istanbul 34755, Turkey

Robert Kiraly - Department of Biochemistry and Molecular Biology, University of Debrecen, Debrecen H4010, Hungary

Laszlo Fesus - Department of Biochemistry and Molecular Biology, University of Debrecen, Debrecen H4010, Hungary

Complete contact information is available at:

https://pubs.acs.org/10.1021/acsomega.0c04226

\section{Author Contributions}

Conceived and designed experiments: D.T. and L.F. Performed the transduction and experiments with mutant RenCa cells: B.U. and T.S. Designed and produced the TG2 mutants: A.B. and R.K. Optimized the experimental methods: A.B. Analyzed data: B.U. Wrote the manuscript: B.U. and D.T.

Notes

The authors declare no competing financial interest.

\section{ACKNOWLEDGMENTS}

This work was supported by the Marie Curie ITN research grant ("TRANSPATH”, FP7 no. 289964). We thank Ayla Burcin Asutay for her technical support in flow cytometry analysis.

\section{ABBREVIATIONS}

TG2, tissue transglutaminase (EC:2.3.2.13); EMT, epithelialmesenchymal transition; RCC, renal cell carcinoma; FN, fibronectin; ECM, extracellular matrix; SDC-4, syndecan-4; ITG $\beta 1$, integrin $\beta 1$; CSC, cancer stem cell; mRCC, metastatic renal cell carcinoma; ITS, insulin transferrin selenium; EGF, epithelial-growth factor; RenCa, renal cell adenocarcinoma cells; FBS, fetal bovine serum; SD, standard deviation; TGF $\beta$ R-II, TGF- $\beta$ receptor II 


\section{REFERENCES}

(1) Collighan, R. J.; Griffin, M. Transglutaminase 2 cross-linking of matrix proteins: biological significance and medical applications. Amino Acids 2009, 36, 659-670.

(2) Nurminskaya, M. V.; Belkin, A. M. Cellular functions of tissue transglutaminase. Int. Rev. Cell Mol. Biol. 2012, 294, 1-97.

(3) Eckert, R. L.; Kaartinen, M. T.; Nurminskaya, M.; Belkin, A. M.; Colak, G.; Johnson, G. V. W.; Mehta, K. Transglutaminase regulation of cell function. Physiol. Rev. 2014, 94, 383-417.

(4) Eckert, R. L.; Fisher, M. L.; Grun, D.; Adhikary, G.; Xu, W.; Kerr, C. Transglutaminase is a tumor cell and cancer stem cell survival factor. Mol. Carcinog. 2015, 54, 947-958.

(5) Belkin, A. M. Extracellular TG2: emerging functions and regulation. FEBS J. 2011, 278, 4704-4716.

(6) Verderio, E. A. M.; Telci, D.; Okoye, A.; Melino, G.; Griffin, M. A novel RGD-independent cel adhesion pathway mediated by fibronectin-bound tissue transglutaminase rescues cells from anoikis. J. Biol. Chem. 2003, 278, 42604-42614.

(7) Telci, D.; Wang, Z.; Li, X.; Verderio, E. A. M.; Humphries, M. J.; Baccarini, M.; Basaga, H.; Griffin, M. Fibronectin-Tissue Transglutaminase Matrix Rescues RGD-impaired Cell Adhesion through Syndecan-4 and $\beta 1$ Integrin Co-signaling. J. Biol. Chem. 2008, 283, 20937-20947.

(8) Wang, Z.; Collighan, R. J.; Gross, S. R.; Danen, E. H. J.; Orend, G.; Telci, D.; Griffin, M. RGD-independent Cell Adhesion via a Tissue Transglutaminase-Fibronectin Matrix Promotes Fibronectin Fibril Deposition and Requires Syndecan-4/2 and $\alpha 5 \beta 1$ Integrin Cosignaling. J. Biol. Chem. 2010, 285, 40212-40229.

(9) Telci, D.; Collighan, R. J.; Basaga, H.; Griffin, M. Increased TG2 Expression Can Result in Induction of Transforming Growth Factor $\beta 1$, Causing Increased Synthesis and Deposition of Matrix Proteins, Which Can Be Regulated by Nitric Oxide. J. Biol. Chem. 2009, 284, 29547-29558.

(10) Mangala, L. S.; Fok, J. Y.; Zorrilla-Calancha, I. R.; Verma, A.; Mehta, K. Tissue transglutaminase expression promotes cell attachment, invasion and survival in breast cancer cells. Oncogene 2006, 26, 2459-2470.

(11) Khanna, M.; Chelladurai, B.; Gavini, A.; Li, L.; Shao, M.; Courtney, D.; Turchi, J. J.; Matei, D.; Meroueh, S. Targeting ovarian tumor cell adhesion mediated by tissue transglutaminase. Mol. Cancer Ther. 2011, 10, 626-636.

(12) Herman, J. F.; Mangala, L. S.; Mehta, K. Implications of increased tissue transglutaminase (TG2) expression in drug-resistant breast cancer (MCF-7) cells. Oncogene 2006, 25, 3049-3058.

(13) Mehta, K.; Fok, J.; Miller, F. R.; Koul, D.; Sahin, A. A. Prognostic Significance of Tissue Transglutaminase in Drug Resistant and Metastatic Breast Cancer. Clin. Cancer Res. 2004, 10, 8068-8076.

(14) Verma, A.; Mehta, K. Tissue transglutaminase-mediated chemoresistance in cancer cells. Elsevier 2007, 10, 144-151.

(15) Agnihotri, N.; Kumar, S.; Mehta, K. Tissue transglutaminase as a central mediator in inflammation-induced progression of breast cancer. Breast Cancer Res. 2013, 15, 202.

(16) Ashour, A. A.; Gurbuz, N.; Alpay, S. N.; Abdel-Aziz, A.-A. H.; Mansour, A. M.; Huo, L.; Ozpolat, B. Elongation factor-2 kinase regulates TG2/ $\beta 1$ integrin/Src/uPAR pathway and epithelialmesenchymal transition mediating pancreatic cancer cells invasion. J. Cell. Mol. Med. 2014, 18, 2235-2251.

(17) Maschler, S.; Wirl, G.; Spring, H.; Bredow, D. V.; Sordat, I.; Beug, H.; Reichmann, E. Tumor cell invasiveness correlates with changes in integrin expression and localization. Oncogene 2005, 24, 2032-2041.

(18) Kumar, A.; Xu, J.; Brady, S.; Gao, H.; Yu, D.; Reuben, J.; Mehta, K. Tissue Transglutaminase Promotes Drug Resistance and Invasion by Inducing Mesenchymal Transition in Mammary Epithelial Cells. PLoS One 2010, 5, No. e13390.

(19) Kumar, A.; Xu, J.; Sung, B.; Kumar, S.; Yu, D.; Aggarwal, B. B.; Mehta, K. Evidence that GTP-binding domain but not catalytic domain of transglutaminase 2 is essential for epithelial-to- mesenchymal transition in mammary epithelial cells. Breast Cancer Res. 2012, 14, R4.

(20) Cao, L.; Petrusca, D. N.; Satpathy, M.; Nakshatri, H.; Petrache, I.; Matei, D. Tissue transglutaminase protects epithelial ovarian cancer cells from cisplatin-induced apoptosis by promoting cell survival signaling. Carcinogenesis 2008, 29, 1893-1900.

(21) Shao, M.; Cao, L.; Shen, C.; Satpathy, M.; Chelladurai, B.; Bigsby, R. M.; Nakshatri, H.; Matei, D. Epithelial-to-Mesenchymal Transition and Ovarian Tumor Progression Induced by Tissue Transglutaminase. Cancer Res. 2009, 69, 9192.

(22) Lin, C.-Y.; Tsai, P.-H.; Kandaswami, C. C.; Chang, G.-D.; Cheng, C.-H.; Huang, C.-J.; Lee, P.-P.; Hwang, J.-J.; Lee, M.-T. Role of tissue transglutaminase 2 in the acquisition of a mesenchymal-like phenotype in highly invasive A431 tumor cells. Mol. Cancer 2011, 10, 87.

(23) Fisher, M. L.; Keillor, J. W.; Xu, W.; Eckert, R. L.; Kerr, C. Transglutaminase is required for epidermal squamous cell carcinoma stem cell survival. Mol. Cancer Res. 2015, 13, 1083-1094.

(24) Fok, J. Y.; Ekmekcioglu, S.; Mehta, K. Implications of tissue transglutaminase expression in malignant melanoma. Mol. Cancer Ther. 2006, 5, 1493-1503.

(25) Miyoshi, N.; Ishii, H.; Mimori, K.; Tanaka, F.; Hitora, T.; Tei, M.; Sekimoto, M.; Doki, Y.; Mori, M. TGM2 is a novel marker for prognosis and therapeutic target in colorectal cancer. Ann. Surg Oncol. 2010, 17, 967-972.

(26) Ayinde, O.; Wang, Z.; Griffin, M. Tissue transglutaminase induces Epithelial-Mesenchymal-Transition and the acquisition of stem cell like characteristics in colorectal cancer cells. Oncotarget 2017, 8, 20025-20041.

(27) Singh, A.; Settleman, J. EMT, cancer stem cells and drug resistance: an emerging axis of evil in the war on cancer. Oncogene 2010, 29, 4741-4751.

(28) Budillon, A.; Carbone, C.; Di Gennaro, E. Tissue transglutaminase: a new target to reverse cancer drug resistance. Amino Acids 2013, 44, 63-72.

(29) Choueiri, T. K.; Motzer, R. J. Systemic Therapy for Metastatic Renal-Cell Carcinoma. N. Engl. J. Med. 2017, 376, 354-366.

(30) Park, M. J.; Baek, H. W.; Rhee, Y.-Y.; Lee, C.; Park, J. W.; Kim, H. W.; Moon, K. C. Transglutaminase 2 Expression and Its Prognostic Significance in Clear Cell Renal Cell Carcinoma. J. Pathol. Transl. Med. 2015, 49, 37-43.

(31) Ku, B. M.; Kim, D. S.; Kim, K. H.; Yoo, B. C.; Kim, S. H.; Gong, Y. D.; Kim, S. Y. Transglutaminase 2 inhibition found to induce p53 mediated apoptosis in renal cell carcinoma. FASEB J. 2013, 27, 3487-3495.

(32) Erdem, S.; Yegen, G.; Telci, D.; Yildiz, I.; Tefik, T.; Issever, H.; Kilicaslan, I.; Sanli, O. The increased transglutaminase 2 expression levels during initial tumorigenesis predict increased risk of metastasis and decreased disease-free and cancer-specific survivals in renal cell carcinoma. World J. Urol. 2015, 33, 1553-1560.

(33) Bagatur, Y.; Ilter Akulke, A. Z.; Bihorac, A.; Erdem, M.; Telci, D. Tissue transglutaminase expression is necessary for adhesion, metastatic potential and cancer stemness of renal cell carcinoma. Cell Adhes. Migr. 2018, 12, 138-151.

(34) Kang, J. H.; Lee, J.-S.; Hong, D.; Lee, S.-H.; Kim, N.; Lee, W.K.; Sung, T.-W.; Gong, Y.-D.; Kim, S.-Y. Renal cell carcinoma escapes death by p53 depletion through transglutaminase 2-chaperoned autophagy. Cell Death Dis. 2016, 7, No. e2163.

(35) Lee, S.-H.; Lee, W.-K.; Kim, N.; Kang, J.; Kim, K.-H.; Kim, S.G.; Lee, J.-S.; Lee, S.; Lee, J.; Joo, J.; Kwon, W.; Rha, S.; Kim, S.-Y. Renal Cell Carcinoma Is Abrogated by p53 Stabilization through Transglutaminase 2 Inhibition. Cancers 2018, 10, 455.

(36) Kim, S.-Y.; Keillor, J. W. A Precision Strategy to Cure Renal Cell Carcinoma by Targeting Transglutaminase 2. Int. J. Mol. Sci. 2020, 21, 2493.

(37) Kundu, S. D.; Kim, I. Y.; Zelner, D.; Janulis, L.; Goodwin, S.; Engel, J. D.; Lee, C. Absence of expression of transforming growth factor-beta type II receptor is associated with an aggressive growth 
pattern in a murine renal carcinoma cell line, Renca. J. Urol. 1998, 160, 1883-1888.

(38) Kerr, C.; Szmacinski, H.; Fisher, M. L.; Nance, B.; Lakowicz, J. R.; Akbar, A.; Keillor, J. W.; Lok Wong, T.; Godoy-Ruiz, R.; Toth, E. A.; Weber, D. J.; Eckert, R. L. Transamidase site-targeted agents alter the conformation of the transglutaminase cancer stem cell survival protein to reduce GTP binding activity and cancer stem cell survival. Oncogene 2017, 36, 2981-2990.

(39) Gundemir, S.; Johnson, G. V. W. Intracellular localization and conformational state of transglutaminase 2: implications for cell death. PLoS One 2009, 4, No. e6123.

(40) Kumar, A.; Gao, H.; Xu, J.; Reuben, J.; Yu, D.; Mehta, K. Evidence that aberrant expression of tissue transglutaminase promotes stem cell characteristics in mammary epithelial cells. PLoS One 2011, 6, No. e20701.

(41) Peired, A. J.; Sisti, A.; Romagnani, P. Renal Cancer Stem Cells: Characterization and Targeted Therapies. Stem Cells Int. 2016, 2016, $1-12$.

(42) Debeb, B. G.; Zhang, X.; Krishnamurthy, S.; Gao, H.; Cohen, E.; Li, L.; Rodriguez, A. A.; Landis, M. D.; Lucci, A.; Ueno, N. T.; Robertson, F.; Xu, W.; Lacerda, L.; Buchholz, T. A.; Cristofanilli, M.; Reuben, J. M.; Lewis, M. T.; Woodward, W. A. Characterizing cancer cells with cancer stem cell-like features in 293T human embryonic kidney cells. Mol. Cancer 2010, 9, 180.

(43) Zhang, Y.; Sun, B.; Zhao, X.; Liu, Z.; Wang, X.; Yao, X.; Dong, $\mathrm{X}$.; Chi, J. Clinical significances and prognostic value of cancer stemlike cells markers and vasculogenic mimicry in renal cell carcinoma. J. Surg. Oncol. 2013, 108, 414-419.

(44) Mann, A. P.; Verma, A.; Sethi, G.; Manavathi, B.; Wang, H.; Fok, J. Y.; Kunnumakkara, A. B.; Kumar, R.; Aggarwal, B. B.; Mehta, K. Overexpression of Tissue Transglutaminase Leads to Constitutive Activation of Nuclear Factor- $\kappa \mathrm{B}$ in Cancer Cells: Delineation of a Novel Pathway. Cancer Res. 2006, 66, 8788-8795.

(45) Kim, D.-S.; Park, S.-S.; Nam, B.-H.; Kim, I.-H.; Kim, S.-Y. Reversal of Drug Resistance in Breast Cancer Cells by Transglutaminase 2 Inhibition and Nuclear Factor- $\kappa \mathrm{B}$ Inactivation. Cancer Res. 2006, 66, 10936-10943.

(46) Yakubov, B.; Chelladurai, B.; Schmitt, J.; Emerson, R.; Turchi, J. J.; Matei, D. Extracellular Tissue Transglutaminase Activates Noncanonical NF- $\kappa$ B Signaling and Promotes Metastasis in Ovarian Cancer. Neoplasia 2013, 15, 609-619.

(47) Jacob, K.; Webber, M.; Benayahu, D.; Kleinman, H. K. Osteonectin promotes prostate cancer cell migration and invasion: a possible mechanism for metastasis to bone. Cancer Res. 1999, 59, $4453-4457$.

(48) Muller, P. A. J.; Trinidad, A. G.; Timpson, P.; Morton, J. P.; Zanivan, S.; van den Berghe, P. V. E.; Nixon, C.; Karim, S. A.; Caswell, P. T.; Noll, J. E.; Coffill, C. R.; Lane, D. P.; Sansom, O. J.; Neilsen, P. M.; Norman, J. C.; Vousden, K. H. Mutant p53 enhances MET trafficking and signalling to drive cell scattering and invasion. Oncogene 2013, 32, 1252-1265.

(49) Shtutman, M.; Levina, E.; Ohouo, P.; Baig, M.; Roninson, I. B. Cell adhesion molecule L1 disrupts E-cadherin-containing adherens junctions and increases scattering and motility of MCF7 breast carcinoma cells. Cancer Res. 2006, 66, 11370-11380.

(50) Paz, H.; Pathak, N.; Yang, J. Invading one step at a time: the role of invadopodia in tumor metastasis. Oncogene 2014, 33, 41934202.

(51) Erdem, M.; Erdem, S.; Sanli, O.; Sak, H.; Kilicaslan, I.; Sahin, F.; Telci, D. Up-regulation of TGM2 with ITGB1 and SDC4 is important in the development and metastasis of renal cell carcinoma. Urol. Oncol. 2014, 32, 25.e13-25.e20.

(52) Gupta, K.; Miller, J. D.; Li, J. Z.; Russell, M. W.; Charbonneau, C. Epidemiologic and socioeconomic burden of metastatic renal cell carcinoma (mRCC): a literature review. Cancer Treat. Rev. 2008, 34, 193-205.

(53) Kim, D. Y.; Karam, J. A.; Wood, C. G. Role of metastasectomy for metastatic renal cell carcinoma in the era of targeted therapy. World J. Urol. 2014, 32, 631-642.
(54) Badarau, E.; Collighan, R. J.; Griffin, M. Recent advances in the development of tissue transglutaminase (TG2) inhibitors. Amino Acids 2013, 44, 119-127.

(55) Yuan, L.; Choi, K.; Khosla, C.; Zheng, X.; Higashikubo, R.; Chicoine, M. R.; Rich, K. M. Tissue transglutaminase 2 inhibition promotes cell death and chemosensitivity in glioblastomas. Mol. Cancer Ther. 2005, 4, 1293-1302.

(56) Antonyak, M. A.; Miller, A. M.; Jansen, J. M.; Boehm, J. E.; Balkman, C. E.; Wakshlag, J. J.; Page, R. L.; Cerione, R. A. Augmentation of tissue transglutaminase expression and activation by epidermal growth factor inhibit doxorubicin-induced apoptosis in human breast cancer cells. J. Biol. Chem. 2004, 279, 41461-41467.

(57) Antonyak, M. A.; Li, B.; Regan, A. D.; Feng, Q.; Dusaban, S. S.; Cerione, R. A. Tissue transglutaminase is an essential participant in the epidermal growth factor-stimulated signaling pathway leading to cancer cell migration and invasion. J. Biol. Chem. 2009, 284, 1791417925.

(58) Satpathy, M.; Cao, L.; Pincheira, R.; Emerson, R.; Bigsby, R.; Nakshatri, H.; Matei, D. Enhanced peritoneal ovarian tumor dissemination by tissue transglutaminase. Cancer Res. 2007, 67, 7194-7202.

(59) Hwang, J. Y.; Mangala, L. S.; Fok, J. Y.; Lin, Y. G.; Merritt, W. M.; Spannuth, W. A.; Nick, A. M.; Fiterman, D. J.; Vivas-Mejia, P. E.; Deavers, M. T.; Coleman, R. L.; Lopez-Berestein, G.; Mehta, K.; Sood, A. K. Clinical and Biological Significance of Tissue Transglutaminase in Ovarian Carcinoma. Cancer Res. 2008, 68, 5849-5858.

(60) Verma, A.; Wang, H.; Manavathi, B.; Fok, J. Y.; Mann, A. P.; Kumar, R.; Mehta, K. Increased expression of tissue transglutaminase in pancreatic ductal adenocarcinoma and its implications in drug resistance and metastasis. Cancer Res. 2006, 66, 10525-10533.

(61) Chhabra, A.; Verma, A.; Mehta, K. Tissue transglutaminase promotes or suppresses tumors depending on cell context. Anticancer Res. 2009, 29, 1909-1919.

(62) Siegel, M.; Khosla, C. Transglutaminase 2 inhibitors and their therapeutic role in disease states. Pharmacol. Ther. 2007, 115, 232245.

(63) Mangala, L. S.; Arun, B.; Sahin, A. A.; Mehta, K. Tissue transglutaminase-induced alterations in extracellular matrix inhibit tumor invasion. Mol. Cancer 2005, 4, 33.

(64) Cao, L.; Shao, M.; Schilder, J.; Guise, T.; Mohammad, K. S.; Matei, D. Tissue transglutaminase links TGF- $\beta$, epithelial to mesenchymal transition and a stem cell phenotype in ovarian cancer. Oncogene 2012, 31, 2521-2534.

(65) Yao, E. S.; Zhang, H.; Chen, Y. Y.; Lee, B.; Chew, K.; Moore, D. Increased betal integrin is associated with decreased survival in invasive breast cancer. Cancer Res. 2007, 67, 659-664.

(66) Boroughs, L. K.; Antonyak, M. A.; Cerione, R. A. A novel mechanism by which tissue transglutaminase activates signaling events that promote cell survival. J. Biol. Chem. 2014, 289, 10115-10125.

(67) Ho, M.-Y.; Tang, S.-J.; Chuang, M.-J.; Cha, T.-L.; Li, J.-Y.; Sun, G.-H.; Sun, K.-H. TNF- $\alpha$ Induces Epithelial-Mesenchymal Transition of Renal Cell Carcinoma Cells via a GSK3 $\beta$-Dependent Mechanism. Mol. Cancer Res. 2012, 10, 1109-1119.

(68) Mani, S. A.; Guo, W.; Liao, M.-J.; Eaton, E. N.; Ayyanan, A.; Zhou, A. Y.; Brooks, M.; Reinhard, F.; Zhang, C. C.; Shipitsin, M.; Campbell, L. L.; Polyak, K.; Brisken, C.; Yang, J.; Weinberg, R. A. The epithelial-mesenchymal transition generates cells with properties of stem cells. Cell 2008, 133, 704-715.

(69) Thiery, J. P.; Acloque, H.; Huang, R. Y.; Nieto, M. A. Epithelialmesenchymal transitions in development and disease. Cell 2009, 139, 871-890.

(70) Gu, K.; Li, M. M.; Shen, J.; Liu, F.; Cao, J. Y.; Jin, S.; Yu, Y. Interleukin-17-induced EMT promotes lung cancer cell migration and invasion via NF- $\kappa \mathrm{B} / \mathrm{ZEB} 1$ signal pathway. Am. J. Cancer Res. 2015, 5, 1169-1179.

(71) Wang, Y.; Zhou, B. P. Epithelial-Mesenchymal Transition-A Hallmark of Breast Cancer Metastasis. Cancer Hallmarks 2013, 1, 3849. 
(72) Park, M. K.; You, H. J.; Lee, H. J.; Kang, J. H.; Oh, S. H.; Kim, S. Y.; Lee, C. H. Transglutaminase-2 induces $\mathrm{N}$-cadherin expression in TGF- $\beta 1$-induced epithelial mesenchymal transition via c-Jun- $\mathrm{N}$ terminal kinase activation by protein phosphatase $2 \mathrm{~A}$ downregulation. Eur. J. Cancer 2013, 49, 1692-1705.

(73) He, W.; Sun, Z.; Liu, Z. Silencing of TGM2 reverses epithelial to mesenchymal transition and modulates the chemosensitivity of breast cancer to docetaxel. Exp. Ther. Med. 2015, 10, 1413-1418.

(74) Fisher, M. L.; Adhikary, G.; Xu, W.; Kerr, C.; Keillor, J. W.; Eckert, R. L. Type II transglutaminase stimulates epidermal cancer stem cell epithelial-mesenchymal transition. Oncotarget 2015, 6, 20525-20539.

(75) Karicheva, O.; Rodriguez-Vargas, J. M.; Wadier, N.; MartinHernandez, K.; Vauchelles, R.; Magroun, N.; Tissier, A.; Schreiber, V.; Dantzer, F. PARP3 controls TGF $\beta$ and ROS driven epithelial-tomesenchymal transition and stemness by stimulating a TG2-Snail-Ecadherin axis. Oncotarget 2016, 7, 64109-64123.

(76) Chen, S.-H.; Lin, C.-Y.; Lee, L.-T.; Chang, G.-D.; Lee, P.-P.; Hung, C.-C.; Kao, W.-T.; Tsai, P.-H.; Schally, A.-V.; Hwang, J.-J.; Lee, M.-T. Up-regulation of fibronectin and tissue transglutaminase promotes cell invasion involving increased association with integrin and MMP expression in A431 cells. Anticancer Res. 2010, 30, 41774186.

(77) Belkin, A. M.; Zemskov, E. A.; Hang, J.; Akimov, S. S.; Sikora, S.; Strongin, A. Y. Cell-Surface-Associated Tissue Transglutaminase Is a Target of MMP-2 Proteolysis. Biochem 2004, 43, 11760-11769.

(78) Erdem, S.; Yegen, G.; Telci, D.; Yildiz, I.; Tefik, T.; Issever, H.; Kilicaslan, I.; Sanli, O. The increased transglutaminase 2 expression levels during initial tumorigenesis predict increased risk of metastasis and decreased disease-free and cancer-specific survivals in renal cell carcinoma. World J. Urol. 2015, 33, 1553-1560.

(79) Jones, R. A.; Kotsakis, P.; Johnson, T. S.; Chau, D. Y. S.; Ali, S.; Melino, G.; Griffin, M. Matrix changes induced by transglutaminase 2 lead to inhibition of angiogenesis and tumor growth. Cell Death Differ. 2006, 13, 1442-1453.

(80) Singh, G.; Zhang, J.; Ma, Y.; Cerione, R. A.; Antonyak, M. A. The Different Conformational States of Tissue Transglutaminase Have Opposing Affects on Cell Viability. J. Biol. Chem. 2016, 291, 9119-9132.

(81) Campeau, E.; Ruhl, V. E.; Rodier, F.; Smith, C. L.; Rahmberg, B. L.; Fuss, J. O.; Campisi, J.; Yaswen, P.; Cooper, P. K.; Kaufman, P. D. A versatile viral system for expression and depletion of proteins in mammalian cells. PLoS One 2009, 4, No. e6529.

(82) Koçak, P.; Canïkyan, S.; Batukan, M.; Attar, R.; Şahïn, F.; Telcï, D. Comparison of enzymatic and nonenzymatic isolation methods for endometrial stem cells. Turk. J. Biol. 2016, 40, 1081-1089.

(83) Carbone, C.; Di Gennaro, E.; Piro, G.; Milone, M. R.; Pucci, B.; Caraglia, M.; Budillon, A. Tissue transglutaminase (TG2) is involved in the resistance of cancer cells to the histone deacetylase (HDAC) inhibitor vorinostat. Amino Acids 2017, 49, 517-528. 